\title{
Operating Reliability Evaluation of Power Systems Considering Flexible Reserve Provider in Demand Side
}

\author{
Heping Jia, Yi Ding, Yonghua Song, Fellow, IEEE, Chanan Singh, Fellow, IEEE and Maozhen Li
}

\begin{abstract}
The development of information and communication technologies and the deregulation of power systems have made the flexible demand participation in bidirectional interaction with power grid possible. The flexible demand can be represented as the flexible reserve provider (FRP) to provide operating reserve through load curtailment and shifting for assisting power system operation. However, the chronological characteristics of curtailment and shifting of FRP may impact the reliability of power systems. Moreover, the uncertainties from customers' participation performances, random failures of information and communication system (ICS), and different load types may also influence system operation. In this paper, a novel operating reliability evaluation model for power systems with FRP is proposed utilizing reliability network equivalent (RNE) and time-sequential simulation (TSS) techniques. The RNE technique is developed to include the reserve capacities of FRP incorporating both chronological characteristics and uncertainties. Optimal operation dispatch for system contingencies considering co-optimization of generation and FRP deployment amount is formulated over the whole study period. The TSS method is utilized to assess the operating reliability of restructured power systems. The proposed approaches are validated using the modified IEEE RTS.
\end{abstract}

Index Terms - operating reliability evaluation, flexible reserve provider, demand side, reliability network equivalent, time-sequential simulation

\section{ABBREVIATIONS}

FRP

ICS

flexible reserve provider

RNE information and communication system

TSS EMFRP

EMGS reliability network equivalent time-sequential simulation equivalent of multi-state FRP equivalent of multi-state generation system

\section{NOMENCLATURE}

$i \quad$ bus index (superscript)

$l, j \quad$ load level index (subscript)

$T \quad$ whole study period

$D_{l}$ duration of the $l$ th load level in the historical load data $L_{l}^{i \prime}(t)$

This work was supported in part by the National Key Research and Development Program of China under Grant 2016YFB0901103, the National Natural Science Foundation of China under Grant 51577167 and 51611130197. Heping Jia, Yi Ding and Yonghua Song are with the College of Electrical Engineering, Zhejiang University, China (e-mail: yiding @ zju.edu.cn).

Chanan Singh is with the Department of Electrical \& Computer Engineering, Texas A\&M University, USA.

Maozhen $\mathrm{Li}$ is with the Department of Electronic and Computer Engineering, Brunel University London, Uxbridge, UB8 3PH, UK.

\section{$L_{l}^{\prime}(t)$}

$\beta$
$M$
$\overline{F S_{l}^{i}}(t)$
$\overline{F C_{l}^{i}}(t)$
$\overline{N D_{l}^{i}}(t)$
$L_{l}^{i}(t)$
$\alpha_{1}, \alpha_{2}, \alpha_{3}$
$m_{l}$
$\bar{m}$
$\overline{\mathbf{F S}} \mathbf{S}_{l}^{i}(t)$
$\overline{F S_{l}^{i, m}}(t)$
$d_{l}^{i, m}$
$\mathbf{d}_{l}^{i}$
$\mathbf{O R}_{l}^{i}$

$\mathbf{F S}_{l}^{i}(t)$

$F S_{l}^{i}(t)$

$F C_{l}^{i}(t)$

$F U_{l}^{i}(t)$

$\mathbf{F S}_{l, j}^{i}(t)$

$F S_{l, j}^{i}(t)$

$F S_{l, j}^{i, m}(t)$

$\Delta t_{l, j}$

$t_{l}$

$C R_{l}^{i}(t)$

$C R_{l}(t)$

$f p_{l, k_{l}}^{i}$

$K_{l}$ number of load sequence for time $T$ number of load levels of the load sequence number of the buses in the system capacity of shiftable load for bus $i$ for state $l$ capacity of curtailable load for bus $i$ for state $l$ capacity of non-dispatchable load for bus $i$ for state $l$ original load for bus $i$ for state $l$ proportions of different load types number of types of shiftable load index for the type of shiftable load (superscript) vector of capacities for different types of shiftable load at bus $i$ for state $l$

capacity of the $m t h$ type of shiftable load at bus $i$ for state $l$

shiftable time period of the $m t h$ type of shiftable load at bus $i$ for state $l$

vector of shiftable time periods for different types of shiftable load at bus $i$ for state $l$

vector of reserve capacity provided by FRP from different types of flexible load at bus $i$ for state $l$ the deployed shifted load of different types of shiftable load at bus $i$ for state $l$

the deployed shifted load from FRP at bus $i$ for state $l$

the deployed shifted load of the mth type of shiftable load from FRP at bus $i$ for state $l$ deployed curtailed load from FRP at bus $i$ for state $l$

$$
\text { unused capacity from FRP for bus } i \text { for state } l
$$

the deployed shifted load of different types of shiftable load from the $l t h$ level to the $j t h$ level at bus $i$ the deployed shifted load from the lth level to the $j t h$ level at bus $i$

the deployed shifted load of the mth type of shiftable load from the $l t h$ level to the $j t h$ level at bus $i$ time interval between the $l$ th state and the $j t h$ state duration of the lth load level for the simulation updated load at bus $i$ for state $l$

updated load for the system for state $l$ actual contribution of load shifting and load curtailment from FRP at bus $i$ for state $l$ actual contribution of load shifting and load curtailment from FRP for the system for state $l$ participation level of FRP for the lth load level number of participation levels for the lth load level 
$\gamma_{l, a_{-} b}^{i} \quad$ transition rate of participation level from $a$ to $b$

$\varepsilon, \mu \quad$ failure rate and repair rate of ICS

$t_{l}^{\text {fail }} \quad$ the time before the failure time of ICS in the lth load level

$S I_{l}^{i} \quad$ the non-recovered shifted energy at bus $i$ for the $l t h$ load level

$\alpha_{q}, \sigma_{q} \quad$ mean value and standard deviation of the proportion for the qth type of load

$\mathbf{A R}_{l}^{i} \quad$ available reserve capacity considering uncertainties provided by FRP at bus $i$ for state $l$

$t_{l, a_{-} b}^{i} \quad$ duration time for the ath participation level

ge generator index (subscript)

$g r \quad$ generator index for reserve (subscript)

$c, s \quad$ FRP index (subscript)

$h \quad$ load sector index (subscript)

$P_{l, g e}^{i}$

$P_{l, g r}^{i}$

$N G$

$N R$

$N S$

$N C$

$\mathrm{NH}$

$T C$

$G C_{l, g e}^{i}(\cdot)$

$R C_{l, g r}^{i}(\cdot)$

$C C_{l, f}^{i}(\cdot)$

$S C_{l, f}^{i, m}(\cdot)$

$I C_{l, h}^{i}(\cdot)$

$\mathrm{LI}_{l}^{i}$

B

$\boldsymbol{\theta}_{l}$

$\overline{P_{l, g e}^{i}}$

$P_{l, g e}^{i}$

$\overline{P_{l, g r}^{i}}$

$\overline{P_{l, g r}^{i}}$

$\overline{L I_{l}^{i}}$

$x_{l}^{i-i^{\prime}}$

$F_{\max }^{i_{i} i^{\prime}}$

$T C^{\prime}$

$\operatorname{EENS}(T)$

$\operatorname{EENS}^{i}(T)$

$\operatorname{LOLP}(t)$

$n_{s}$ the generation at bus $i$ for state $l$

the reserve from generation at bus $i$ for state $l$

number of generating units

number of generation reserve units

number of FRP through shifting

number of FRP through curtailment

number of customers that can be interrupted

total system cost over the whole study period

generation cost

generation reserve cost

compensation cost for curtailment of FRP

compensation cost for shifting of FRP

interruption cost of customers

customer interruption at bus $i$ for state $l$

admittance matrix of transmission network

the phase angle vector of bus voltages

upper limit of power generation

lower limit of power generation

upper limit of reserve from generation

lower limit of reserve from generation

the reactance of the transmission line between bus $i$ and bus $i$ '

maximum power flow of the transmission line

between bus $i$ and bus $i$ '

updated total system cost considering interruption

caused by the failure of ICS

expected energy not supplied of the system for the study period $T$

expected energy not supplied of the system for the study period $T$ at bus $i$

loss of load probability of the system at time $t$

the sampling number of the simulation upper limit of the load interruption

\section{INTRODUCTION}

$\mathrm{W}$ ITH the integration of the time-varying load and fluctuant renewable energy generation, massive operating reserve is required for maintaining a secure and reliable power system. The operating reserve can be classified into primary reserve, secondary reserve, and tertiary reserve from the point of view of their time of deployment after occurring a system disturbance [1]. The primary control occurs within seconds of a disturbance, where the goal is to keep the system frequency within a prearranged range through governor when the system experiences small load variations or sudden generation loss. The secondary control is within several minutes associated with normal load-following, where the goal is to restore frequency to its nominal value and to manage the loading of inter-area transmission facilities [2]. The goal of the tertiary reserve provision is to impose a new post-contingency set point with zero area control error that also meets all prescribed transmission flow constraints [1]. Conventional operating reserve is generally provided by traditional generating units. However, from the perspective of operating period for power systems, load variation, random failures of system components and system operational conditions have significant influences on system reliability and availability [3]. The researches on operating or short-term reliability analysis for power systems have been extensively studied [4]-[7] . Analytic methods including universal generating function [8], Markov process [9], [10], and simulation techniques [11] are generally utilized in reliability evaluation for power systems. Reliability network equivalent (RNE) techniques [12]-[15] have been conducted in reliability assessment for composite power systems to decrease computation efforts and simplify the analytical procedures [15]. Simulation methods have been applied in reliability analysis because of the flexibility in simulating particular characteristics and complex operation conditions of power systems [11].

However, operating reserve provided by conventional generations may be costly for operation and maintenance and aggravate environmental pollution. Under the framework of smart grid, active participation of flexible demand such as air conditioners and electric vehicles has become a new tendency for assisting the operation of restructured power systems [16]. Flexible demand can be aggregated as flexible reserve provider (FRP) in demand side to provide operating reserve to the systems. In this paper, the FRP provides tertiary reserve in the system operation. Considering different operation time of various flexible demand, FRP can provide operating reserve capacities by implementing two main strategies: curtailment and shifting. The load curtailment can be achieved through bilateral contracts with reasonable economic compensation to the customers. Some industrial customers can interrupt their loads as a method of providing reserve to the systems. The load shifting indicates that customers can shift load from peak hours or contingency periods to other time with incentives. For instance, some residential customers can postpone or advance the usage of electricity appliances such as washing machines or electrical vehicles to release demand during peak hours. Utilizing FRP to supply operating reserve capacities is promising [17], [18] and can achieve more than 20\% load 
reduction during peak hours [18].

Notice that, the bidirectional interaction between FRP and power grids may considerably impact the reliability of power systems due to the efficiency of FRP. Since the load curtailment and shifting strategies are time-dependent, the chronological characteristics of reserve capacities provided through these two strategies may influence the operation state of power systems. Moreover, the stochastic behaviors of customers' electricity consumption may adversely affect the available reserve capacities which in turn impact the system reliability [16]. Additionally, with deeper integration of information and communication system (ICS) [19], the uncertainties from random failures of ICS may notably affect the reserve capacities provided by FRP as well. Therefore, the reserve capacities of FRP considering chronological characteristics and multiple uncertainties in restructured power systems are imperative to be thoroughly analyzed and quantitatively evaluated.

Considerable studies have been devoted to the reliability evaluation of systems considering devices or resources in demand side. The reliability [20] and adequacy analysis [21] of power system with energy storage integration have been proposed without the consideration of changeable load by demand response. The reliability impacts of electric vehicles represented as energy storage devices on power systems have been assessed in [22]. For the perspective of chronological characteristics when conducting DR, the load reduction is considered for the probabilistic reliability evaluation of power systems in [23] . However, the impacts of previous load control strategies on the current or other time periods such as load shifting are neglected. For the perspective of multiple uncertainties when FRP providing operating reserve, the uncertainties of participation performances are incorporated in the elasticity estimation of DR programs [16]. However, a random variable added in elasticity may not particularly formulate the stochastic behaviors of customers. Random failures of demand side resources are considered to obtain the probabilities of their capacities focused on cases where resources in demand side have the battery-like characteristics in [24]. However, the model may be not applicable to residential customers [24].

In this paper, we explore the impacts of reserve capacities provided by FRP in demand side on system reliability by considering the chronological characteristics when implementing load curtailment and shifting. Moreover, the uncertainties existing in reserve capacities provided by FRP are analyzed considering the customers' behaviors, random failures of ICS, and different load types. Considering huge computational burden of DR with various customers, we extend RNE techniques to include the reserve capacities provided by FRP through equivalent multi-state FRP (EMFRP). Both of the chronological characteristics and uncertainties are embedded in the equivalent, specifically. Furthermore, in order to explore the impacts of FRP on composite system reliability, an optimal power flow model over the whole study period is proposed considering the equivalent for multi-state generations, random failures of transmission network and reserve capacities provided by FRP.

The remainder of the paper is organized as follows. Section II proposes the EMFRP considering chronological characteristics of curtailment and shifting, and uncertainties from participation level of customers, random failures of ICS as well as different load types. The operation dispatch for contingency states is developed to achieve minimal system cost in Section III. The TSS technique is utilized to evaluate the reliability of power systems with FRP in Section IV. A modified IEEE RTS [25] is utilized to depict the validity of the proposed approach in Section V. Section VI gives the conclusions of this paper.

\section{RNE FOR FRP}

In the restructured power systems, the flexible demand from residential, industrial and commercial customers, such as electric vehicles, air conditioners, heat pumps and other responsive equipment, can be aggregated into FRP to provide reserve capacities for power systems.

In order to explore the reliability impacts of FRP on power systems, FRP can be demonstrated as EMFRP utilizing RNE methods. The chronological characteristics of curtailment and shifting, and uncertainties from customers' participation performances, random failures of ICS and different load types are considered in the EMFRP. Fig.1 describes the RNE for FRP.

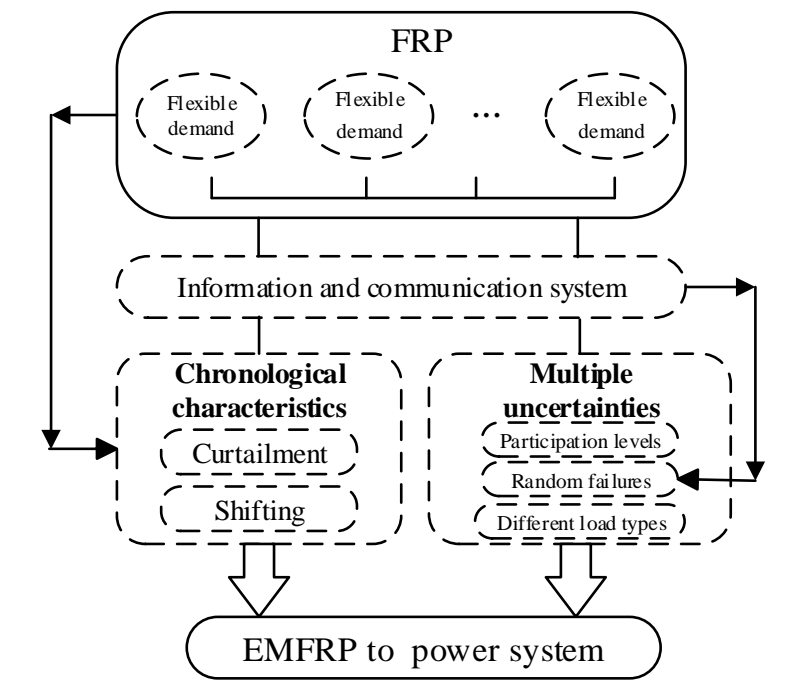

Fig.1. RNE for FRP

\section{A. Multi-state Model Considering Chronological Characteristics of FRP}

To explore the reserve capacities provided by FRP, the characteristics of FRP are supposed to be analyzed. In this paper, the conventional load model [26] without its flexibility represented in multi-state model is developed to formulate the time-varying characteristics of FRP. In Reference [26], the whole duration of study period $T$ is predetermined by the system operator. It can be one day, one week, even one year. For the $T$ time period, the load can be divided into $\beta$ sequence of load levels. Each set of sequence of load levels can be 
divided into $M$ different load levels with different duration times $D_{l}$ from the historical load data as shown in Fig. 2. Usually, $\beta$ is equal to 1 . The summation of the time durations of each load level is the total study period $T$ as shown in Eq. (1). For example, the total study period $T$ can be one week.

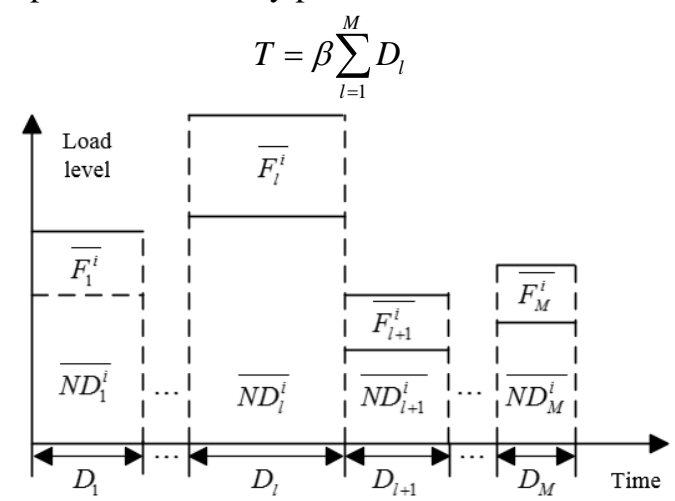

Fig. 2 The sequence of load levels

The presented multi-state load model in Reference [26] illustrates $\beta$ sequence of $M$ load levels which are sequentially connected as they appear in the historical load data. In the Markov load model, the transition rate of the lth load level $\lambda_{l}$ can be obtained as Eq. (2).

$$
\lambda_{l}=1 / D_{l}
$$

After obtaining the load levels and transition rates between different load levels, the Markov load model can be presented as Fig. 3. The presented Markov load model has been successfully applied to the reliability evaluation of power systems [27]-[29]. The main idea of the Markov load model is to keep the chronological representation of load and uncertainties in the duration times of different load levels. In order to improve the accuracy of the load model, the number of sets of sequence of load levels $\beta$ in a study period $T$ can be reduced to 1 where there is no repeat for sets of sequence. Moreover, the number of load levels in the sequence is supposed to be as many as possible in some degree.

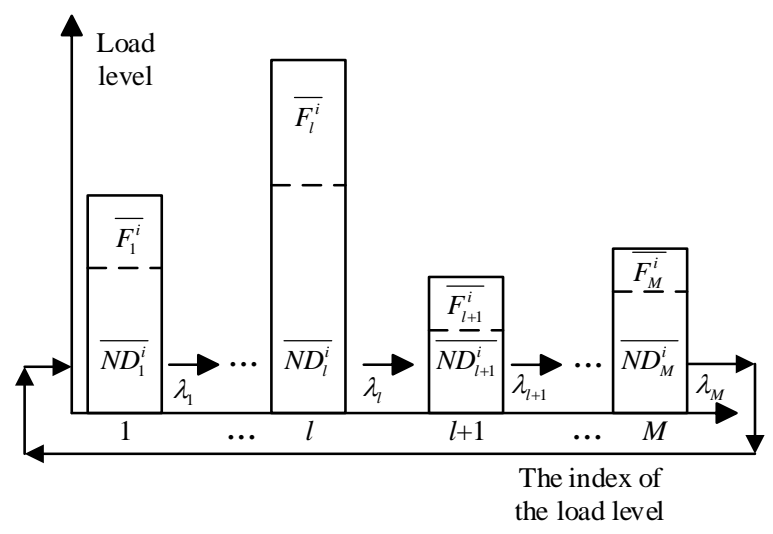

Fig.3. Multi-state load model at bus $i^{\prime}$

The load can be divided into $M$ states which are sequentially connected and located at $N$ buses. $L_{l}^{i}(t)(i=1, \cdots, N ; l=1, \cdots, M)$ indicates the load in the $l$ th state at the $i$ th bus. The multi-state load model imposes the same variation pattern for all load buses. Therefore, the assumption that all the bus loads are perfectly correlated are made [26].

The load can be divided into shiftable load, curtailable load, and non-dispatchable load. The shiftable load and curtailable load can be uniformed as flexible load. Especially, there exist different types of shiftable load. The capacity of shiftable load can be divided into $m_{l}$ types at bus $i$ for state $l$. The capacity of the mth type of shiftable load at bus $i$ for state $l$ can be represented as $\overline{F S_{l}^{i, m}}(t)$. The capacities of different load types at bus $i$ for state $l$ can be denoted as $\overline{F S_{l}^{i}}(t), \overline{F C_{l}^{i}}(t)$, and $\overline{N D_{l}^{i}}(t)$, where $\overline{F S_{l}^{i}}(t)=\sum_{m=1}^{m_{l}} \overline{F S_{l}^{i, m}}(t)$. The capacity of flexible load at bus $i$ for state $l$ is $\overline{F_{l}^{i}}(t)$. The proportions of each load type can be different and formulated as $\alpha_{1}, \alpha_{2}, \alpha_{3}$. Then, we have

$$
\left\{\begin{array}{l}
\overline{F S_{l}^{i}}(t)=\alpha_{1} L_{l}^{i}(t) \\
\overline{F C_{l}^{i}}(t)=\alpha_{2} L_{l}^{i}(t) \\
\overline{N D_{l}^{i}}(t)=\alpha_{3} L_{l}^{i}(t) \\
\alpha_{1}+\alpha_{2}+\alpha_{3}=1
\end{array}\right.
$$

Especially, for the shiftable load, different types of shiftable load at bus $i$ for state $l$ can be represented as a vector $\overline{\mathbf{F S}_{l}^{i}}(t)$ :

$$
\overline{\mathbf{F S}_{l}^{i}}(t)=\left[\overline{F S_{l}^{i, 1}}(t), \cdots, \overline{F S_{l}^{i, m}}(t), \cdots, \overline{F S_{l}^{i, m_{l}}}(t)\right]^{T}
$$

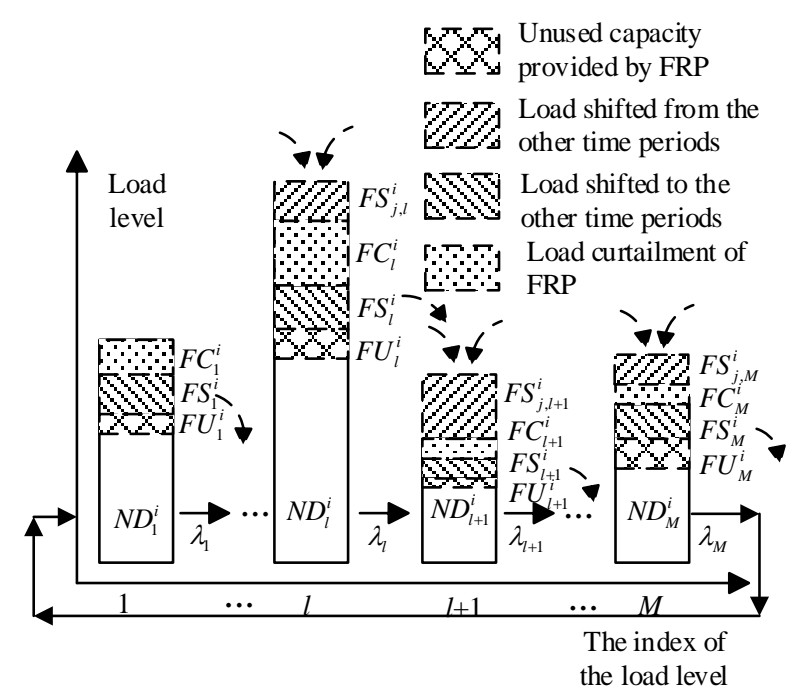

Fig.4. Multi-state load model when curtailment and shifting happen

The maximum shiftable time period of the $m_{l}$ types of shiftable load can be demonstrated as a vector $\mathbf{d}_{l}^{i}$ :

$$
\mathbf{d}_{l}^{i}=\left[d_{l}^{i, 1}, \cdots, d_{l}^{i, m}, \cdots, d_{l}^{i, m_{l}}\right]
$$

The reserve capacity provided by FRP from different types of flexible load for bus $i$ at time $t$ can be formulated as a vector $\mathbf{O R}_{l}^{i}$ :

$$
\mathbf{O R}_{l}^{i}=\left[\begin{array}{l}
\overline{\mathbf{F S}}_{l}^{i}(t) \\
\overline{F C_{l}^{i}}(t)
\end{array}\right]
$$

Fig.4 illustrates the multi-state load model when curtailment 
and shifting happen based on the conventional load model. The original flexible load capacity can be represented as:

$$
\begin{aligned}
& \overline{F_{l}^{i}}(t)=F S_{l}^{i}(t)+F C_{l}^{i}(t)+F U_{l}^{i}(t) \\
& =\sum_{m=1}^{m_{l}} F S_{l}^{i, m}(t)+F C_{l}^{i}(t)+F U_{l}^{i}(t)
\end{aligned}
$$

In Eq. (7), $F S_{l}^{i}(t), F C_{l}^{i}(t)$ and $F U_{l}^{i}(t)$ indicate the deployed shifted load, deployed curtailed load, and unused capacity of FRP for state $l$ at bus $i$, respectively. $F S_{l}^{i, m}(t)$ denotes the deployed shifted load of the $m t h$ type shiftable load. The vector $\mathbf{F S}_{l}^{i}(t)$ can be utilized to present the deployed shifted load from the $m$ th type of shiftable load at bus $i$.

$$
\mathbf{F S}_{l}^{i}(t)=\left[F S_{l}^{i, 1}(t), \cdots, F S_{l}^{i, m}(t), \cdots, F S_{l}^{i, m_{l}}(t)\right]^{T}
$$

The load shifted from the $l$ th state to the $j$ th state can be represented as $\mathbf{F S}_{l, j}^{i}(t)(j \neq l)$, where

$$
\mathbf{F S}_{l, j}^{i}(t)=\left[F S_{l, j}^{i, 1}(t), \cdots, F S_{l, j}^{i, m}(t), \cdots, F S_{l, j}^{i, m_{l}}(t)\right]^{T}
$$

$F S_{l, j}^{i, m}(t)(j \neq l)$ is the deployed load shifted from the $l$ th state to the $j$ th state .

It should be noted that if the shiftable time period $d_{l}^{i, m}$ is smaller than the time interval between the lth state and the $j t h$ state $\Delta t_{l, j}$, the $m t h$ type shiftable load would not be deployed. It can be formulated as Eq. (10).

$$
F S_{l, j}^{i, m}(t)=0, \text { if } d_{l}^{i, m}<\Delta t_{l, j}
$$

Moreover, considering the possible different durations of time periods, the constraint that the deferred energy from load shifting equals to the incurred energy is conducted. In the proposed model, the shifted energy from the lth load level is equal to the energy shifted to the other load levels. That is to say, for the lth state, the shifting energy should meet Eq. (11).

$$
\mathbf{F S}_{l}^{i}(t) \cdot t_{l}=\sum_{j \neq l}^{M} \mathbf{F} \mathbf{S}_{l, j}^{i}(t) \cdot t_{j}
$$

where $t_{l}$ indicates the duration time of the $l$ th load level in the Markov load model.

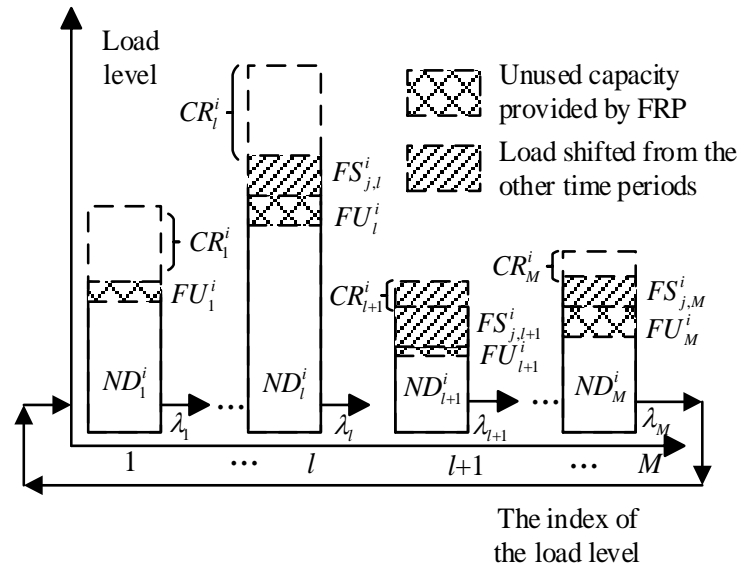

Fig.5. Multi-state load model after curtailment and shifting

For the load curtailment and load shifting, the corresponding strategy is to minimize the total system cost utilizing optimal power flow technique. More details are demonstrated in Section III.B.
After the curtailment and shifting processes of FRP, the load at bus $i$ can be updated as presented in Fig. 5 .

The updated load $L_{l}^{i^{\prime}}(t)$ in the $l$ th state at bus $i$ can be formulated as:

$$
\begin{aligned}
& L_{l}^{i^{\prime}}(t)=N D_{l}^{i}(t)+F U_{l}^{i}(t)+\sum_{j \neq l}^{M} \sum_{m=1}^{m_{l}} F S_{j, l}^{i, m}(t)(l=1, \cdots, M) \\
& =L_{l}^{i}(t)+\sum_{j \neq l}^{M} \sum_{m=1}^{m_{l}} F S_{j, l}^{i, m}(t)-F C_{l}^{i}(t)-F S_{l}^{i}(t)(l=1, \cdots, M) \\
& =L_{l}^{i}(t)+\sum_{j \neq l}^{M} \sum_{m=1}^{m_{l}} F S_{j, l}^{i, m}(t)-F C_{l}^{i}(t)-\sum_{j \neq l}^{M} \sum_{m=1}^{m_{l}} F S_{l, j}^{i, m}(t)(l=1, \cdots, M)
\end{aligned}
$$

The updated load of the system is:

$$
L_{l}^{\prime}(t)=\sum_{i=1}^{N} L_{l}^{i^{\prime}}(t)
$$

For the bus $i$, the actual contribution of load shifting and load curtailment from FRP in the $l$ th state can be formulated as $C R_{l}^{i}(t)$ :

$$
\begin{aligned}
& C R_{l}^{i}(t)=L_{l}^{i^{\prime}}(t)-L_{l}^{i}(t) \\
& =\sum_{j \neq l}^{M} \sum_{m=1}^{m_{l}} F S_{j, l}^{i, m}(t)-F C_{l}^{i}(t)-\sum_{j \neq l}^{M} \sum_{m=1}^{m_{l}} F S_{l, j}^{i, m}(t)(l=1, \cdots, M)
\end{aligned}
$$

From the overall prospective, for the lth state at bus $i$, if $C R_{l}^{i}(t)>0$, it indicates the load increases after the adjustment of demand response and FRP provides down reserve for the system. Conversely, the load reduces and FRP provides up reserve for the system.

The total contribution of load shifting and load curtailment from FRP to the system can be calculated by the summation of the actual contribution for each bus:

$$
C R_{l}(t)=\sum_{i=1}^{N} C R_{l}^{i}(t)
$$

\section{B. Multi-state Model Considering Uncertainties from FRP}

The capacity of operating reserve provided by FRP is not only related to the chronological characteristics of FRP, but also associated with the uncertainties from FRP. The uncertainties are from stochastic behaviors of customers, random failures of ICS, and different load types which may influence the operating capacity of FRP. The uncertainties from the stochastic behaviors of customers can be represented as multi-state model to formulate the participation levels from full participation state with $100 \%$ proportion to non-participation state with zero proportion. Coordinating uncertainties from both customers' stochastic behaviors and random failures of ICS, a notable multi-state model for uncertainties of FRP is developed as shown in Fig. 6.

The participation level of FRP is dependent on the behaviors of customers to some extent and can be derived from historical database. Customers' electricity consumption behaviors may be effected by factors like the incentive mechanism or weather conditions. $f p_{l, k_{l}}^{i}$ represents the participation level of FRP.

There are $K_{l}$ participation levels for the $l$ th state. Specifically, $f p_{l, 1}^{i}$ and $f p_{l, K_{l}}^{i}$ represent FRP in the full participation state and 
non-participation state, respectively. The transition rate of participation level from $a$ to $b$ is designated as $\gamma_{l, a_{-} b}^{i}$.

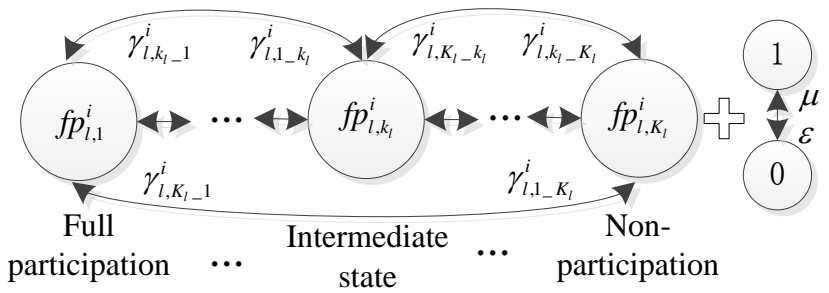

Fig.6. Multi-state model considering uncertainties from both customers' participation levels and random failures of ICS

Remarkably, the development of information and communication technologies has made significant contributions to power systems. ICS has become an indispensable part to realize the active participation of FRP under the smart grid framework. However, uncertainties from ICS including random failures of its physical system may affect the participation level of FRP. State-space based methods have been developed to capture necessary information about the physical system [30]. Binary-state models have been widely applied in reliability evaluation for engineering systems [31] to demonstrate the perfect functioning state and complete failure state. In this paper, we use binary-state model to illustrate the reliability model of uncertainties from ICS for FRP. The failure rate and repair rate of ICS are presented as $\varepsilon$ and $\mu$. If the ICS is in perfect functioning state, the state is represented as "1". Otherwise, if the ICS is in complete failure state, the state is represented as " 0 ".

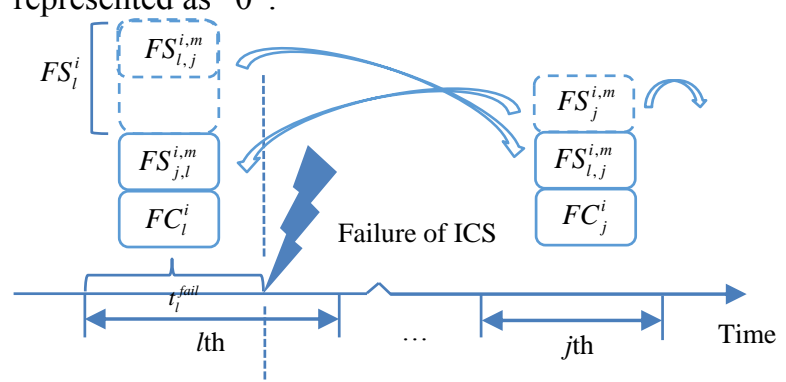

Fig.7. The failure of ICS

Moreover, it should be noted that the failure of ICS would impact the implementation of load shifting. If the ICS is in failure in the $l$ th time period after it starts $t_{l}^{\text {fail }}$ time, the load shifting would be stopped immediately. In this case, the mth type of shiftable load shifted from other time periods to the $l$ th time period $F S_{j, l}^{i, m}(j \neq l)$ would only last for $t_{l}^{\text {fail }}$ time and cannot be fully recovered. Therefore, the shifted load with the remaining $\left(t_{l}-t_{l}^{\text {fail }}\right)$ time in the $l$ th time period which is not recovered is supposed to be calculated in the reliability indices. The energy loss that should be supplemented in the reliability indices under this condition is presented as Eq. (16).

$$
S I_{l}^{i}=\sum_{j \neq l}^{M} \sum_{m=1}^{m_{l}} F S_{j, l}^{i, m}(t) \cdot\left(t_{l}-t_{l}^{\text {fail }}\right)
$$

In the model description above, we assume that the value of non-dispatchable load, curtailable load and shiftable load are predesigned without uncertainties. However, in reality, there exist uncertainties which are supposed to be considered. The uncertainties from proportions of different load types as presented in Eq. (3) can be reasonably described by normal distributions $N \sim\left(\alpha_{q}, \sigma_{q}^{2}\right)(q=1,2,3)$ [4]. $\alpha_{q}$ and $\sigma_{q}$ are the mean value and standard deviation of the proportion for the $q$ th type of load.

\section{The EMFRP Considering Both Chronological Characteristics and Uncertainties}

Considering both chronological characteristics and uncertainties of FRP, the multi-state model for EMFRP can be illustrated in Fig. 8. The EMFRP can arrange the reserve capacities in power pool or through bilateral contracts under the framework of restructured power systems.

The available reserve capacity considering uncertainties provided by EMFRP at time $t$ should be revised based on Eq. (6) and represented as Eq. (17):

$$
\mathbf{A R}_{l}^{i}=\mathbf{O} \mathbf{R}_{l}^{i} \cdot f p_{l, k_{l}}^{i}=\left[\begin{array}{c}
\overline{\mathbf{F S}}_{l}^{i}(t) \\
\overline{F C_{l}^{i}}(t)
\end{array}\right] \cdot f p_{l, k_{l}}^{i}
$$

which takes values from $\mathbf{O R}_{l}^{i} \cdot\left\{f p_{l, 1}^{i}, \cdots, f p_{l, k_{l}}^{i}, \cdots, f p_{l, K_{l}}^{i}\right\}$.

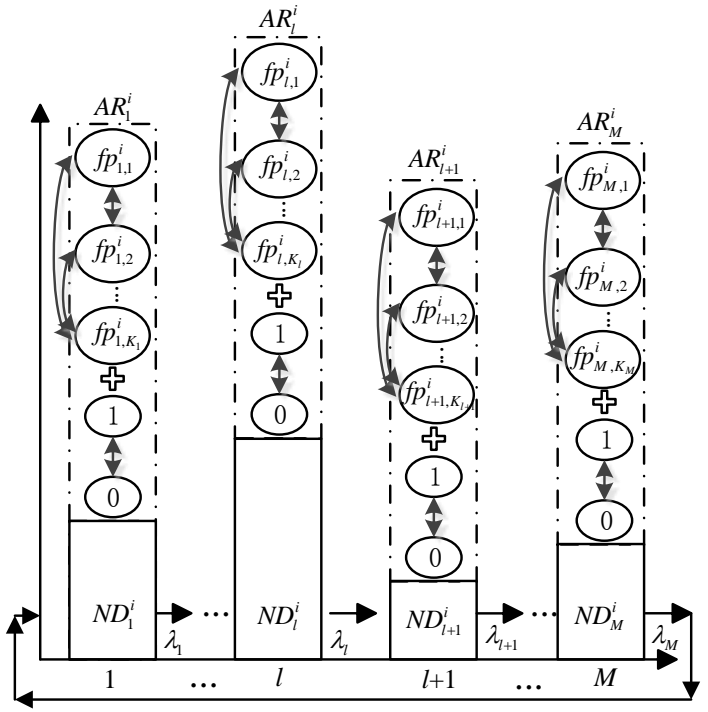

Fig.8. Multi-state model for EMFRP

The TSS procedures to determine the characteristics of the EMFRP are elaborated as follows.

$>$ Step 1: Simulate the multiple state sequences of original load including the state and corresponding state duration time which follows the corresponding exponential distribution as shown in Section II.A.

The duration sequence of each load state is determined by the load state transition rates. The load state transition rates $\lambda_{l}$ are assumed to be known based on the historical load data. For the simulation, the duration time of the load state can be obtained as $t_{l}=-\frac{1}{\lambda_{l, l+1}} \ln U$, where $U$ is a 
uniformly distributed random variable over the interval $(0,1)$ [32]. Simulating the load sequence utilizing this technique until the whole study period $T$ is satisfied.

$>$ Step 2: Suppose the proportion of the capacity for different types of flexible load, including the curtailable load and different types of shiftable load in the operation period based on the original load sequence.

$>$ Step 3: For each state $l$, simulate the state sequences of participation level of FRP which follow the corresponding exponential distribution in Section II. B utilizing the similar technique in Step 1.

For state $l$, the duration sequence of participation level of FRP is determined by the transition rates $\gamma_{l, a_{-} b}^{i}$ between participation levels. Considering the transition rates of customer's participation from state $a$ to state $b$ for the $l$ th load level at bus $i$, the duration time for the ath participation level is $t_{l, a_{-} b}^{i}=-\frac{1}{\gamma_{l, a_{-} b}^{i}} \ln U(b \neq a)$, where $U$ is a uniformly distributed random variable over the interval $(0,1)[32]$. Then, find the minimal duration time $t_{l, a_{-} b}^{i, \min }$ from all $t_{l, a_{-} b}^{i}$ where $b \neq a$. The ath participation level will transit to the bth participation level with the minimal duration time $t_{l, a_{-} b}^{i, \min }$. Since the transition rates between different participation levels are formally dependent on the load state $l$, utilizing this approach, the participation level can be obtained for each state $l$. Repeat this process for all load states, the sequences of participation level can be obtained for the whole study period.

$>$ Step 4: Simulate the state sequence of ICS based on the failure rate and repair rate utilizing the similar technique in Step 3.

$>$ Step 5: Determine the actual participation level utilizing the participation level of FRP multiplied by the state of ICS.

$>$ Step 6: Make the reserve capacities of FRP multiplied by the actual participation level to determine the available reserve capacities provided by FRP according to Eq. (17).

$>$ Step 7: Formulate the optimal power flow in Section III to determine the deployed reserve provided by FRP. In the optimization problem, the load shifting, load curtailment and customer interruption are conducted.

\section{OPtimal OPERATION DisPatch FOR CONTINGENCIES CONSIDERING FRP}

When the power system is in the contingency state, power generation and reserve capacities of EMFRP are supposed to be re-dispatched and some customers may be interrupted to sustain the balance of power system.

In order to analyze the reliability of power systems considering generation systems, transmission systems and FRP as a whole, in this section, we first discuss the uncertainties of generation system to explore the influences on the deliverability of electric power. The RNE for generation system is introduced. Moreover, considering contingencies such as transmission system failures, operation dispatch based on optimal power flow is developed to achieve minimal system cost by co-optimizing both generation and FRP deployment amount. The optimal operation dispatch for system in contingency state is demonstrated in Fig. 9.

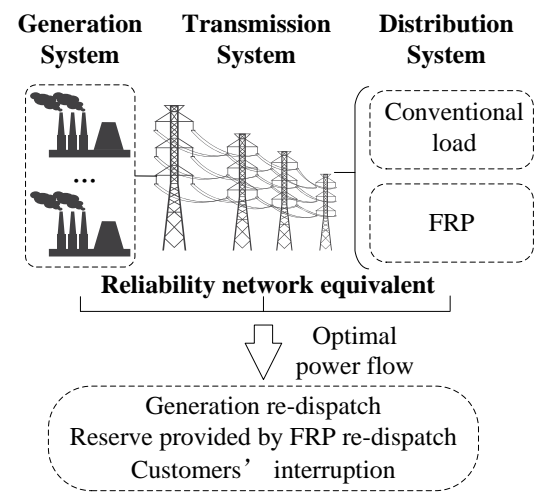

Fig.9. Optimal operation dispatch for system in contingency state

\section{A. RNE for Generation System}

In the restructured power systems, generation system usually consists of several large conventional generating units for trading electric power and reserve in forward and real-time balancing markets [33]. These generating units are under economic dispatch in normal operation states and can supply reserve capacities during contingencies. Generating units are of great significance for providing electric power and maintaining system reliability in the restructured power systems.

Considering the characteristics of controllability and stochasticity of large conventional generating units, the RNE can be demonstrated as equivalent multi-state generation system (EMGS) instead of simply binary states. The characteristics for EMGS can be determined utilizing TSS technique in [11].

\section{B. Operation Dispatch Based on Optimal Power Flow}

Considering the random failures of transmission network, the operation dispatch is developed based on optimal power flow model, where the generation and FRP are dispatched to achieve minimal system cost considering the significance of economic benefits in the restructured power systems. It should be noted that the reliability data including the failure rates and repair rates of the system components usually can be obtained from historical failure statistics [34] and can be estimated from the observed realization of the stochastic process for components' performance [34]. Using these information, possible scenarios and reasonable actions within these scenarios can be generated. Knowing the scenario does give foresight to the dispatcher. However, although the study period may be one week but duration for the dispatcher decision for a particular load state may be much shorter considering the time-varying characteristic of load. So the period for a given dispatch action is not long, it provides a reasonable description of the dispatcher action.

The optimization objective is to minimize the total system cost, including the generation cost, the reserve cost from generating units, the compensation cost for curtailment and 
shifting of FRP, and interruption cost of customers as presented in Eq. (18). Since the load level $l$ is dependent with time $t, t$ is omitted for simplification in the optimization problem.

$$
\begin{aligned}
& \operatorname{Min} T C=\sum_{l}^{M} \sum_{i=1}^{N}\left\{\sum_{g e=1}^{N G} G C_{l, g e}^{i}\left(P_{l, g e}^{i}\right)+\sum_{g r=1}^{N R} R C_{l, g r}^{i}\left(P_{l, g r}^{i}\right)\right. \\
& \left.+\sum_{c=1}^{N C} C C_{l, c}^{i}\left(F C_{l}^{i}\right)+\sum_{s=1}^{N S} \sum_{m=1}^{m_{l}} S C_{l, s}^{i, m}\left(F S_{l}^{i, m}\right)+\sum_{h=1}^{N H} I C_{l, h}^{i}\left(L I_{l}^{i}\right)\right\}
\end{aligned}
$$

The shifting and curtailment from FRP are under the framework of demand response. Both of the curtailment and shifting are supposed to be informed to customers in advance. The compensation costs for curtailment and shifting can be determined by the contracts between the electricity utilities and customers or the bids of demand response customers in the energy market [35]. Moreover, the interruption of customers indicate a blackout and it could incur economic loss for customers. Therefore, it is essential to calculate this kind of interruption into reliability indices. The interruption cost of customers depends on the type of customers, duration of the interruption, and so on [36]. The interruption costs of customers are formulated as customer damage functions for different types of customers, which are functions of the interruption durations [37]. The evaluated interruption costs have been studied by the US Department of Energy for a variety of customer categories utilizing statistical regression techniques to identify the best fitting customer damage functions from the historcal data [38]. As one of the most widely used metric for expressing interruption costs, the expected cost of unserved energy is utilized in this paper.

Eq. (18) is subject to the following constraints:

Power balance constraints:

$$
\left(\mathbf{B} \cdot \boldsymbol{\theta}_{l}\right)^{i}=\sum_{g e=1}^{N G} P_{l, g e}^{i}+\sum_{g r=1}^{N G} P_{l, g r}^{i}-L_{l}^{i^{\prime}}
$$

Generation limits:

$$
\underline{P_{l, g e}^{i}} \leq P_{l, g e}^{i} \leq \overline{P_{l, g e}^{i}}
$$

Limits of reserve capacity from generation:

$$
\underline{P_{l, g r}^{i}} \leq P_{l, g r}^{i} \leq \overline{P_{l, g r}^{i}}
$$

Capacity limits of FRP considering both curtailment and shifting:

$$
\mathbf{0} \leq\left[\begin{array}{c}
\mathbf{F S}_{l}^{i} \\
F C_{l}^{i}
\end{array}\right] \leq \mathbf{A R}_{l}^{i}
$$

Customer interruption constraints:

$$
0 \leq L I_{l}^{i} \leq \overline{L I_{l}^{i}}
$$

Line flow constraints:

$$
\left|\frac{1}{x_{l}^{i-i^{\prime}}}\left(\theta_{l}^{i}-\theta_{l}^{i^{\prime}}\right)\right| \leq\left|F_{\max }^{i-i^{\prime}}\right|
$$

Constraints from load shifting as presented in Eq. (10) and (11).

In the formulation of the optimization problem, $\mathbf{B}$ and $\boldsymbol{\theta}_{l}$ represent the admittance matrix of transmission network and the phase angle vector of bus voltages, respectively. $\overline{P_{l, g e}^{i}}$ and
$\underline{P_{l, g e}^{i}}, \overline{P_{l, g r}^{i}}$ and $\underline{P_{l, g r}^{i}}$ are the upper limit and lower limit of power generation and generation reserve, respectively. $\overline{L I_{l}^{i}}$ is the upper limit of customer interruption. It is determined by the characteristic of the load. $x_{l}^{i_{-} i^{\prime}}$ and $F_{\max }^{i_{-} i^{\prime}}$ denote the reactance and maximum power flow of the transmission line between bus $i$ and bus $i$, respectively.

It should be noted that if there is a failure of ICS in the system operation, customers are supposed to be interrupted. The total interruption cost $T C^{\prime}$ will be updated by supplementing the interruption cost caused by the failure of ICS as shown in Eq. (25). It should be noted that during the system operation, if a failure of ICS occurs, there might be unsuccessful response where shiftable load cannot be recovered due to the failure of ICS. Thus, the consequences including the cost and interrupted load (Eq. (16) and (25)) are supposed to be modified when decisions on the system operation are implemented.

$$
T C^{\prime}=T C+\sum_{l=1}^{M} \sum_{h=1}^{N H} I C_{l, h}^{i}\left[\sum_{j \neq l}^{M} \sum_{m=1}^{m_{l}} F S_{j, l}^{i, m}(t) \cdot\left(t_{l}-t_{l}^{f a i l}\right)\right]
$$

\section{TSS PROCEDURES FOR RELIABILITY EVALUATION OF POWER SYSTEMS WITH FRP}

In the simulation, two reliability indices of power systems are calculated. The expected energy not supplied (EENS) and instant loss of load probability (LOLP) are utilized to demonstrate the reliability of the restructured power systems. For the system operation, the indices are re-defined to evaluate the operating reliability of power systems to evaluate the time-vary reliabilities of power systems [11]. Moreover, it should be noted that the shifted load which is not recovered because of the failure of ICS is supposed to be supplemented in the reliability indices. They can be formulated in Eq. (26)-(28):

$$
\begin{gathered}
\operatorname{EENS}(T)=\left\{\sum_{n=1}^{n_{s}} \sum_{i=1}^{N}\left[\int_{0}^{T} L I_{l}^{i}(t) \cdot d t+\sum_{l=1}^{M} S I_{l}^{i}\right]\right\} / n_{s} \\
\operatorname{EENS}^{i}(T)=\left\{\sum_{n=1}^{n_{s}}\left[\int_{0}^{T} L I_{l}^{i}(t) \cdot d t+\sum_{l=1}^{M} S I_{l}^{i}\right]\right\} / n_{s} \\
\operatorname{LOLP}(t)=\sum_{j=1}^{n_{s}} m_{j}(t) / n_{s}
\end{gathered}
$$

where $n_{s}$ indicates the sampling number of the simulation. In Eq. (28), $m_{j}(t) \in\{0,1\}$. If there is no load interruption and non-recovered shifted load, $m_{j}(t)=0$; Otherwise, if there is load interruption or non-recovered shifted load, $m_{j}(t)=1$.

The steps below are the TSS procedures for evaluating reliability of the restructured power systems considering FRP.

Step 1: Generate the state sequence for the EMGS at each bus for the study time period, e.g., one week, utilizing the TSS technique in [11]. Determine the state of the EMGS at time $t$ according to the sampled sequence.

Step 2: Generate the state sequence for the load at each bus for the study time period utilizing the procedures described in Section II.C. Determine the state of the load at time $t$ as well as 
the available reserve capacity of FRP according to the sampled sequence.

Step 3: The optimal power flow model introduced in Section III.B is utilized to assess the customer interruption at each bus at time $t$. If the system suffers from customer interruption, then the system is in failure state at time $t$.

Step 4: According to the state sequence of ICS, determine the shifted energy which is not recovered due to the failure of ICS based on Eq. (16).

Step 5: Go to Step 1 until the confidence intervals are satisfied. Otherwise, go to Step 6.

The stopping criterion given for the simulation is the EENS coefficient of variation.

$$
\beta_{E E N S}=\sqrt{V(\operatorname{EENS}(T))} / \operatorname{EENS}(T)
$$

where $V(E E N S(T))$ is the variance of $\operatorname{EENS}(T)$.

Step 6: Calculate the average reliability indices of the power system according to Eq. (26)-(28) and update the total system cost if there is a failure of ICS.

\section{CASE STUdies}

The modified IEEE RTS [25] is restructured to demonstrate the proposed models and techniques. Four 575-MW coal thermal generating units, two 197-MW oil thermal generating units and five 50-MW hydro generating units are installed in the system [11]. The 575-MW coal thermal generating units are presented in four-state Markov process model which is utilized in real engineering systems [34]. In practical, the initial state of the system is usually determined by the system operator. It can be "all-up" state with all generating units in up states or some generating units in failure states. The change of generation capacity due to the random failure with the time increase of system operation is usually studied and utilized in the reliability evaluation of power systems [39]. In these cases, the initial states for the generating units are set to be "all-up" states as their installed generation capacities: 575MW, 197MW, and $50 \mathrm{MW}$, respectively. The locations and bidding coefficients for the power generation [36] are presented in TABLE I. The utilization cost for the generation reserve is assumed to be $20 \$ / M W h$ higher than its generation price.

The whole duration of study period is 168 hours (1 week). The load levels are with five weekdays and one weekend. The hourly peak load over a daily time period in a summer week presented in [40] can be divided into four categories [16]: valley (2-6h, 58\%), flat 1 (6-9h, 87\%), peak $(9-22 \mathrm{~h}, 100 \%)$ and flat $2(22-2 \mathrm{~h}, 87 \%)$ in weekdays and valley $(2-8 \mathrm{~h}, 66 \%)$, flat 1 (8-10h, $86 \%)$, peak $(10-22 \mathrm{~h}, 100 \%)$ and flat $2(22-2 \mathrm{~h}, 88 \%)$ in weekend. The transition rates of different load levels for weekdays and weekend are shown in TABLE II. The start time for the study period is determined by the system operator, which can be at any time point. Therefore, the initial state of the load is the load level at the start time of the study period. In these cases, the initial state for the load level is assumed as the load level at time 0 in a weekday. It is a flat load level with $87 \%$ of the peak load. The compensation cost for the load shifting and load curtailment are presented in TABLE I as well. The interruption cost per unserved $\mathrm{kWh}$ for customers with different interruption duration [38] are presented in TABLE III. The upper limit of customer interruption is the amount of total load which denotes all of the load can be interrupted when the system contingency occurs. The stopping criterion for the simulation is $\beta_{E E N S} \leq 0.01$.

TABLE I

THE LOCATIONS AND UNIT COSTS FOR THE GENERATION UNITS AND FRP

\begin{tabular}{|c|c|c|c|}
\hline \multirow{2}{*}{$\begin{array}{c}\text { Generating } \\
\text { unit }\end{array}$} & \multirow{2}{*}{ Location(bus) } & \multicolumn{2}{|c|}{ Bidding coefficient } \\
\hline & & $\mathrm{a}\left(\$ / \mathrm{MW}^{2} \mathrm{~h}\right)$ & $\mathrm{b}(\$ / \mathrm{MWh})$ \\
\hline $50 \mathrm{MW} * 3$ & 2 & 0.1 & 0.5 \\
\hline $197 \mathrm{MW}^{* 2} 2$ & 13 & 0.4 & 50.6 \\
\hline $575 \mathrm{MW}^{* 4}$ & $15,16,18,23$ & 0.05 & 12.1 \\
\hline $50 \mathrm{MW} * 2$ & 21 & 0.1 & 0.5 \\
\hline \multirow{2}{*}{ Load } & \multirow{2}{*}{ Location(bus) } & \multicolumn{2}{|c|}{ Cost (\$/MWh) } \\
\hline & & Shifting & Curtailment \\
\hline Residential & $1,2,3,4,5$ & 50 & 100 \\
\hline $\begin{array}{l}\text { Commercial } \\
\text { Industrial }\end{array}$ & $\begin{array}{r}6,7,8,9,10,13 \\
14,15,16,18,19,20\end{array}$ & 70 & 150 \\
\hline
\end{tabular}

TABLE II

TRANSITION RATES OF DIFFERENT LOAD LEVELS FOR WEEKDAYS AND WEEKEND

\begin{tabular}{ccccc}
\hline \hline Transition rates(/hour) & Valley & Flat 1 & Peak & Flat 2 \\
\hline Valley & -- & $1 / 4,1 / 6$ & 0 & 0 \\
Flat 1 & 0 & -- & $1 / 3,1 / 2$ & 0 \\
Peak & 0 & 0 & - & $1 / 13,1 / 12$ \\
Flat 2 & $1 / 4,1 / 4$ & 0 & 0 & -- \\
\hline \hline
\end{tabular}

TABLE III

THE INTERRUPTION COST FOR DIFFERENT CUSTOMERS WITH DIFFERENT INTERRUPTION DURATIONS [38]

\begin{tabular}{cccccc}
\hline \hline \multirow{2}{*}{$\begin{array}{c}\text { Cost }(\$ / \\
\text { unserved } \\
\mathrm{kWh})\end{array}$} & 0.01 & 0.5 & 1 & 4 & 8 \\
\cline { 2 - 6 } & 16.8 & 3.5 & 2.2 & 1.2 & 0.9 \\
\hline Residential & \multicolumn{5}{c}{ Interruption duration(hour) } \\
$\begin{array}{c}\text { Commercial/ } \\
\text { Industrial }\end{array}$ & 96.5 & 22.6 & 15.3 & 13.0 & 10.6 \\
\hline \hline
\end{tabular}

\section{A. Case 1: Different Operating Reserve Capacities of FRP}

The operating reserve provided by FRP with four different proportions of the total original load is studied in this case. The proportions of shiftable load and curtailable load for different scenarios are listed in TABLE IV. Considering the load shifting usually occur within one day, it is assumed that the load can be shifted to the next three time periods in this case. Uncertainties are not considered in this case. That is to say, the FRP are in full participation level.

TABLE IV

THE PROPORTIONS OF SHIFTABLE LOAD AND CURTAILABLE LOAD FOR

\begin{tabular}{ccccc}
\multicolumn{5}{c}{ DIFFERENT SCENARIOS IN CASE 1 } \\
\hline \hline Scenario & $\mathrm{A}$ & $\mathrm{B}$ & $\mathrm{C}$ & $\mathrm{D}$ \\
\hline Load shifting & 0 & 0.05 & 0.1 & 0.15 \\
Load curtailment & 0 & 0.05 & 0.1 & 0.15 \\
\hline FRP & 0 & 0.1 & 0.2 & 0.3 \\
\hline \hline
\end{tabular}

TABLE V

SYSTEM EENS AND RELATIVE DIFFERENCES FOR SCENARIOS IN CASE 1

\begin{tabular}{ccc}
\hline \hline Scenario & EENS (MWh) & Relative difference \\
\hline A & 1142.51 & 0 \\
B & 395.47 & $-65.38 \%$ \\
C & 101.38 & $-91.13 \%$ \\
D & 63.43 & $-94.45 \%$ \\
\hline \hline
\end{tabular}




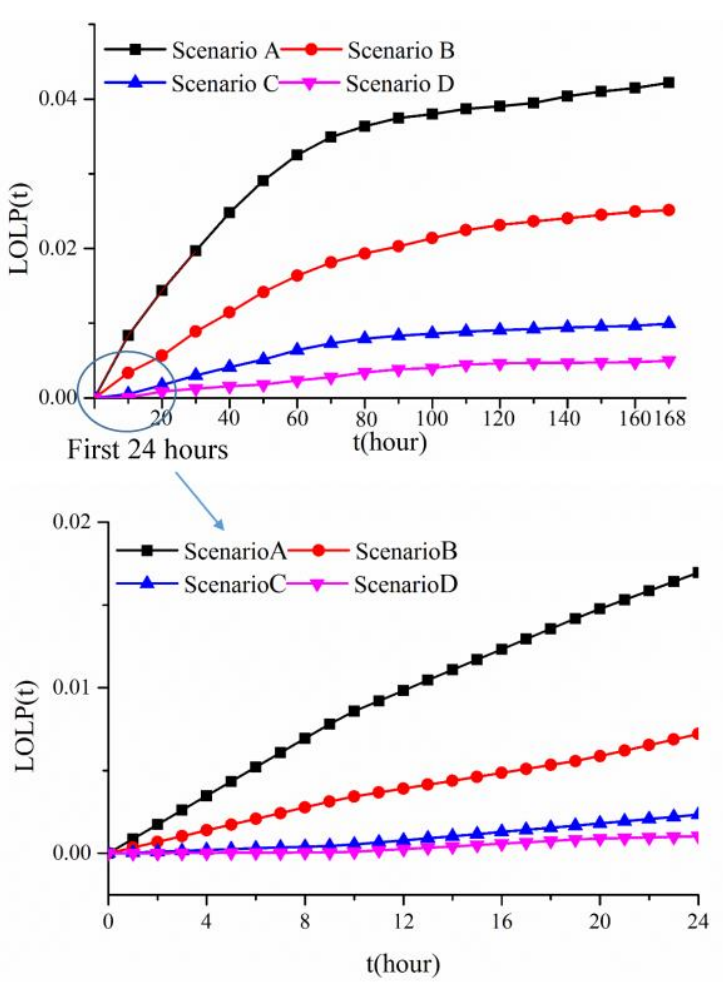

Fig. 10. System LOLP of Case 1

TABLE VI

SYSTEM COSTS FOR SCENARIOS IN CASE 1(\$)

\begin{tabular}{ccccc}
\hline \hline Scenario & $\mathrm{A}$ & $\mathrm{B}$ & $\mathrm{C}$ & $\mathrm{D}$ \\
\hline Generation & $32,278,302$ & $31,463,027$ & $31,210,852$ & $31,089,518$ \\
Reserve & $2,630,146$ & $1,871,678$ & $1,235,416$ & $1,189,572$ \\
Shifting & 0 & 662,838 & $1,101,018$ & $1,173,866$ \\
Curtailment & 0 & 129,050 & 149,583 & 162,686 \\
Interruption & $5,440,792$ & $1,444,604$ & 316,508 & 169,484 \\
\hline Total cost & $40,349,240$ & $35,571,197$ & $34,013,377$ & $33,785,126$ \\
\hline \hline
\end{tabular}

The system without FRP is discussed as the base scenario (Scenario A). TABLE V tabulates system EENS for 168 hours (one week) and the relative differences compared with the base scenario. The time-varying LOLP for different scenarios of Case 1 are depicted in Fig. 10. Total system cost is illustrated in TABLE VI.

It can be observed from TABLE V and Fig.10 that the system reliability indices (EENS and LOLP) without considering the impacts of FRP are larger than those in other scenarios where the reserve capacities of FRP are taken into account. Moreover, the reliability of systems with more FRP is higher than that of systems with less capacity of FRP. From TABLE VI, we can observe that with the increasing capacities provided by FRP, there are more compensation cost for the load shifting and curtailment. Moreover, with more interruption of customers, the system cost is higher.

\section{B. Case 2: Uncertainties from FRP}

In this case, the uncertainties from the customer's behaviors and random failures of ICS as well as the uncertainty of different load types are discussed.

In order to make comparison, Scenario A, B and C of Case 2 include the uncertainties from FRP. The information of participation levels for FRP including full participation (level 1, $100 \%$ ), intermediate state 1 (level 2,60\%), intermediate state 2 (level 3,30\%) and non-participation (level 4, 0\%). The initial sate of the participation level is assumed as the full participation level. For simplification of the simulation, the transition rates between different participation levels for each load state are assumed to be the same as shown in TABLE VII. The failure rate and repair rate of ICS are $8 * 10^{-4} /$ hour and $0.02 /$ hour [41].

TABLE VII

TRANSITION RATES BETWEEN DIFFERENT PARTICIPATION LEVELS OF CUSTOMERS

\begin{tabular}{ccccc}
\hline \hline Transition rates(/hour) & Level 1 & Level 2 & Level 3 & Level 4 \\
\hline Level 1 & -- & 0.067 & 0.016 & 0.016 \\
Level 2 & 0.359 & -- & 0.185 & 0.038 \\
Level 3 & 0.155 & 0.192 & -- & 0.122 \\
Level 4 & 0.018 & 0.008 & 0.013 & -- \\
\hline \hline
\end{tabular}

The mean values of the proportions of shiftable load and curtailable load are listed in TABLE VIII. The standard deviation of them is 0.01 . Other conditions are the same as those in Case 1, correspondingly.

TABLE VIII

THE MEAN VALUES OF PROPORTIONS FOR SHIFTABLE LOAD AND CURTAILABLE LOAD FOR DIFFERENT SCENARIOS IN CASE 2

\begin{tabular}{cccc}
\hline \hline Scenario & A & B & C \\
\hline Load shifting & 0.15 & 0.1 & 0.2 \\
\hline Load curtailment & 0.15 & 0.2 & 0.1 \\
\hline \hline
\end{tabular}

TABLE IX

SYSTEM EENS AND COSTS FOR SCENARIOS IN CASE 2

\begin{tabular}{ccccc}
\hline \hline Scenario & $\begin{array}{c}\text { EENS } \\
(\mathrm{MWh})\end{array}$ & $\begin{array}{c}\text { Relative } \\
\text { difference }\end{array}$ & $\begin{array}{c}\text { Interruption } \\
\text { cost }(\$)\end{array}$ & $\begin{array}{c}\text { Total } \\
\text { cost }(\$)\end{array}$ \\
\hline $\mathrm{A}$ & 440.12 & 0 & $1,734,953$ & $35,857,945$ \\
$\mathrm{~B}$ & 392.59 & $-10.80 \%$ & $1,520,108$ & $35,646,100$ \\
$\mathrm{C}$ & 467.72 & $6.27 \%$ & $2,030,840$ & $36,133,832$ \\
\hline \hline
\end{tabular}

TABLE IX presents the system EENS, interruption cost, and total cost for the study period of Case 2. It can be seen from TABLE IX that the system reliability varies with different proportions of shiftable load and curtailable load. Compared with Scenario D in Case 1, the uncertainties from FRP significantly influence the system reliability. Moreover, with more curtailable load, the system is more reliable with lower system EENS and lower total system cost.

\section{Case 3: Different Shiftable Time Periods}

In this case, different scenarios with different shiftable time periods are analyzed. In Scenario A, the load can be shifted only to the next one hour while in Scenario B and C, the load can be shifted to the next three hours and next five hours, respectively. The shiftable capacity and curtailable capacity are $15 \%$ and $15 \%$ of the total load.

The system EENS for one week and system LOLP are presented in TABLE X and Fig. 11, respectively.

TABLE X

SYSTEM EENS AND COSTS FOR SCENARIOS IN CASE 3

\begin{tabular}{ccccc}
\hline \hline Scenario & $\begin{array}{c}\text { EENS } \\
(\mathrm{MWh})\end{array}$ & $\begin{array}{c}\text { Relative } \\
\text { difference }\end{array}$ & $\begin{array}{c}\text { Shifting } \\
\text { cost }(\$)\end{array}$ & $\begin{array}{c}\text { Total } \\
\text { cost }(\$)\end{array}$ \\
\hline $\mathrm{A}$ & 844.32 & $91.84 \%$ & 549,524 & $37,671,374$ \\
$\mathrm{~B}$ & 484.60 & $10.10 \%$ & 676,998 & $36,221,672$ \\
$\mathrm{C}$ & 440.12 & 0 & 694,889 & $35,857,945$ \\
\hline \hline
\end{tabular}




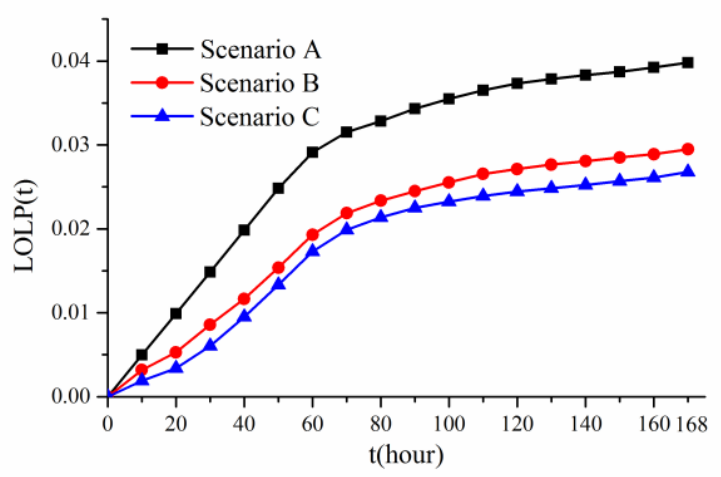

Fig.11. System LOLP of Case 3

It can be observed from TABLE $X$ and Fig. 11 that if the shiftable time periods are not limited, the system with longer shiftable time periods is more reliable. Moreover, the total system cost is lower while the shifting cost is higher. It is because that with longer shiftable time periods, the shiftable load is more likely to be transferred the other time periods when the system is in peak hours or contingency state.

\section{Case 4: Different Locations of FRP}

In order to demonstrate the significant influence of the location of FRP, bus 3 is assumed to be the "weak" bus, where two transmission lines connected to the bus are assumed to be in failure. The shiftable capacity and curtailable capacity are $15 \%$ and $15 \%$ of the total load. In Scenario A, the FRP are distributed located proportionally to the load at each bus. In Scenario B, the reserve capacity of FRP is aggregated to bus 3 .

TABLE XI

SYSTEM EENS AND COSTS FOR SCENARIOS IN CASE 4

\begin{tabular}{ccccc}
\hline \hline Scenario & $\begin{array}{c}\text { EENS } \\
(\mathrm{MWh})\end{array}$ & $\begin{array}{c}\text { Relative } \\
\text { difference }\end{array}$ & $\begin{array}{c}\text { Interruption } \\
\text { cost }(\$)\end{array}$ & $\begin{array}{c}\text { Total } \\
\text { cost }(\$)\end{array}$ \\
\hline $\mathrm{A}$ & 533.04 & 0 & $2,319,789$ & $36,707,133$ \\
$\mathrm{~B}$ & 376.59 & $-29.35 \%$ & $1,416,731$ & $35,582,250$ \\
\hline \hline
\end{tabular}

TABLE XI presents the system EENS for one week and system costs. Fig. 12 illustrates the EENS for one week at each bus. It can be observed from the comparison that when the FRP is located at the bus 3, the system total EENS is lower. The EENS at bus 3 is significantly reduced when the FRP is aggregated at that bus. It is because the system suffers a congestion in Scenario A. The reserve cannot be transmitted to the bus where it is needed. From Fig. 12, we can see that the EENS at buses 1-5 where the residential customers are located are higher compared with that of other types of customers. It is because the residential customers located at buses 1-5 are with lower interruption cost. When solving the optimization problem which minimizes the total system cost over the whole study period, the customers with lower interruption cost are more likely to suffer from the interruption.

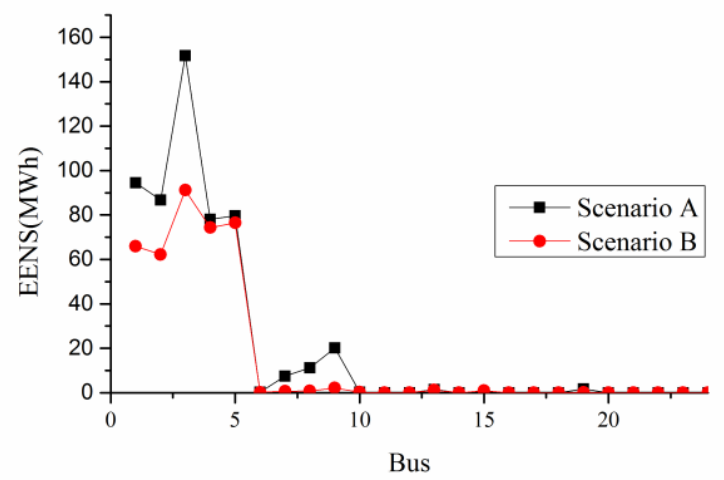

Fig.12. EENS at different buses in Case 4

\section{E. Case 5: Load Model with Fixed Time Steps}

In order to demonstrate the flexibility of the proposed framework for the reliability evaluation of power system considering FRP in demand side, the load model with fixed time steps is utilized. In other words, no uncertainties from the durations of each load level are considered. In this case, the curtailable load and shiftable load are half of the total FRP, respectively.

Fig. 13 illustrates the system EENS for one week with different proportions of FRP with fixed time steps in load model. It can be seen without considering the uncertainties of duration times of load levels in the load modeling, the system EENS is lower compared with Scenario A in Case 1 and Scenario C in Case 3. Moreover, with the proportion growth of FRP participating in the power system operation, the system EENS decreases before a certain threshold. Then, the system EENS varies little when the proportion of FRP is approaching and beyond the threshold. It indicates that considering both chronological characteristics and uncertainties of FRP, providing more possible operating reserve capacities by FRP does not necessarily lead to the higher reliability of systems. Utilities of power systems can balance the cost of FRP and reliability of systems when implementing electric investment and development planning.

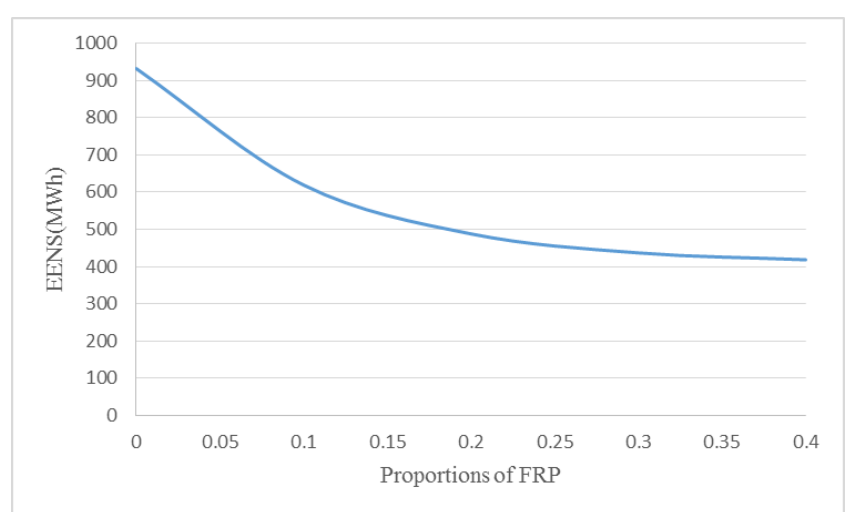

Fig. 13. System EENS with different proportions in Case 5

\section{CONCLUSIONS}

Under the framework of smart grid, FRP in demand side can provide operating reserve for power systems through load curtailment and shifting. In this paper, the RNE technique is 
developed to include the reserve capacities of FRP. The chronological characteristics and uncertainties of FRP are embedded in the RNE based on multi-state model. The chronological characteristics of curtailment and shifting and uncertainties from customers' participation levels, random failures of ICS and different load types are analyzed for the FRP. Moreover, the operation dispatch utilizing FRP to provide operating reserve for system contingencies is developed to achieve minimal system operation cost. The proposed techniques provide a flexible approach to reliability assessment for restructured power system with FRP. Five cases are analyzed in the modified IEEE RTS and the reliability indices as well as the system costs are quantitatively presented. The case studies show that the uncertainties existing in FRP, the shiftable time period and the location of FRP do affect the system reliability. Moreover, it should be pointed out that the proposed framework is flexible and the load model with fixed time steps can be utilized. Furthermore, there might be a threshold of the FRP proportion for the system reliability improvement. Note that the case studies illustrate the intuitive knowledge that with more FRP in demand side, the system would have higher reliability. We, however, note that the objective in computing the reliability indices is the quantification considering FRP in demand side. The quantitative evaluation instead of qualitative or intuitive analysis can provide values for decision making for the system operation.

\section{REFERENCES}

[1] F. D. Galiana, F. Bouffard, J. M. Arroyo and J. F. Restrepo, "Scheduling and Pricing of Coupled Energy and Primary, Secondary, and Tertiary Reserves," in Proceedings of the IEEE, vol. 93, no. 11, pp. 1970-1983, Nov. 2005.

[2] "Glossary of terms," Glossary of Terms Task Force, North American Electric Reliability Council, Aug. 1996 [Online]. Available:ftp://www.nerc.com/pub/sys/all_updl/docs/pubs/glossv10.pdf

[3] R. Sun, C. Singh, L. Cheng, Y. Sun, "Short-term reliability evaluation using control variable based dagger sampling method," Electric Power Systems Research, vol. 80, pp. 682-689, 2010.

[4] R. Billinton, N. R. Allan, in Reliability Evaluation of Power Systems, 2nd ed., Plenum, 1996.

[5] A. D. Patton, C. Singh and M. Sahinoglu, "Operating Considerations in Generation Reliability Modeling-An Analytical Approach," IEEE Transactions on Power Apparatus and Systems, vol. PAS-100, no. 5, pp. 2656-2663, May 1981.

[6] C. Singh, et al., "Operating considerations in reliability modeling of interconnected systems-an analytical approach," IEEE Transactions on Power Systems, vol. 3, no. 3, pp. 1119-1126, Aug. 1988.

[7] Y. Sun, L. Cheng, X. Ye, J. He and P. Wang, "Overview of power system operational reliability," in 2010 IEEE 11th International Conference on Probabilistic Methods Applied to Power Systems, Singapore, 2010, pp. 166-171.

[8] Y. Ding, C. Singh, L. Goel, J. Østergaard and P. Wang, "Short-Term and Medium-Term Reliability Evaluation for Power Systems With High Penetration of Wind Power," IEEE Transactions on Sustainable Energy, vol. 5, no. 3, pp. 896-906, July 2014.

[9] Y. Sun, P. Wang, L. Cheng and H. Liu, "Operational reliability assessment of power systems considering condition-dependent failure rate," IET Generation, Transmission \& Distribution, vol. 4, no. 1, pp. 60-72, January 2010.

[10] Y. Yan, Y. Ding, C. Guo, R. Wang, L. Cheng and Y. Sun, "Operating Reliability Analysis of Peaking Generating Units Considering Start-Up Failures and Degradation," in 2016 Second International Symposium on Stochastic Models in Reliability Engineering, Life Science and Operations Management (SMRLO), Beer Sheva, 2016, pp. 168-171.

[11] Y. Ding, L. Cheng, Y. Zhang, et al. "Operational reliability evaluation of restructured power systems with wind power penetration utilizing reliability network equivalent and time-sequential simulation approaches," Journal of Modern Power Systems \& Clean Energy, vol. 2, no. 4, pp. 329-340, Dec. 2014.

[12] R. Billinton and P. Wang, "Deregulated power system planning using a reliability network equivalent technique,"IEE Proceedings - Generation, Transmission and Distribution, vol. 146, no. 1, pp. 25-30, Jan 1999.

[13] P. Wang and R. Billinton, "Reliability assessment of a restructured power system using reliability network equivalent techniques," IEE Proceedings-Generation, Transmission and Distribution, vol. 150, no. 5, pp. 555-560, 15 Sept. 2003.

[14] P. Wang, R. Billinton and L. Goel, "Unreliability cost assessment of an electric power system using reliability network equivalent approaches," IEEE Transactions on Power Systems, vol. 17, no. 3, pp. 549-556, Aug 2002.

[15] A. Mehrtash, P. Wang and L. Goel, "Reliability Evaluation of Power Systems Considering Restructuring and Renewable Generators," IEEE Transactions on Power Systems, vol. 27, no. 1, pp. 243-250, Feb. 2012.

[16] A. Moshari, A. Ebrahimi and M. Fotuhi-Firuzabad, "Short-Term Impacts of DR Programs on Reliability of Wind Integrated Power Systems Considering Demand-Side Uncertainties," IEEE Transactions on Power Systems, vol. 31, no. 3, pp. 2481-2490, May 2016.

[17] The Brattle Group, Freeman, Sullivan \& Co and Global Energy Partners, LLC, "A National Assessment of Demand Response Potential," Federal Energy Regulatory Commission, June 2009.

[18] Staff report, "Assessment of demand response and advanced metering," Federal Energy Regulatory Commission, Dec. 2008.

[19] T. Jin and M. Mechehoul, "Ordering Electricity via Internet and its Potentials for Smart Grid Systems," IEEE Transactions on Smart Grid, vol. 1, no. 3, pp. 302-310, Dec. 2010.

[20] Y. Xu and C. Singh, "Power System Reliability Impact of Energy Storage Integration With Intelligent Operation Strategy," IEEE Transactions on Smart Grid, vol. 5, no. 2, pp. 1129-1137, March 2014.

[21] P. Wang, Z. Gao and L. Bertling, "Operational Adequacy Studies of Power Systems with Wind Farms and Energy Storages," IEEE Transactions on Power Systems, vol. 27, no. 4, pp. 2377-2384, Nov. 2012.

[22] L. Cheng, Y. Chang, J. Lin and C. Singh, "Power System Reliability Assessment With Electric Vehicle Integration Using Battery Exchange Mode," IEEE Transactions on Sustainable Energy, vol. 4, no. 4, pp. 1034-1042, Oct. 2013.

[23] J. Choi, J. Lim and K. Y. Lee, "DSM Considered Probabilistic Reliability Evaluation and an Information System for Power Systems Including Wind Turbine Generators," IEEE Transactions on Smart Grid, vol. 4, no. 1, pp. 425-432, March 2013.

[24] J. Zhang, A. Dominguez-Garcia, "Evaluation of Demand Response Resource Aggregation System Capacity under Uncertainty," IEEE Transactions on Smart Grid. doi: 10.1109/TSG.2017.2663780

[25] Reliability Test System Task Force of the Application of Probability Methods Subcommittee, "IEEE reliability test system," IEEE Transactions on Power Apparatus and Systems, vol. 98, no. 6, pp. 2047-2054, Nov./Dec. 1979.

[26] A. M. Leite da Silva, L. A. da Fonscca Manso, J. C. de Oliveira Mello, R. Billinton, "Pseudo-chronological simulation for composite reliability analysis with time varying loads," IEEE Transactions on Power Systems, vol. 15, no. 1, pp. 73-80, Feb. 2000.

[27] R. Billinton, C. Singh, "System Load Representation in Generating Capacity Reliability Studies Part I Model Formulation and Analysis," IEEE Transactions on Power Apparatus and Systems, vol.PAS-91, no. 5, pp. 2125-2132, Sept. 1972.

[28] Y. Wang, Q. Chen, C. Kang and Q. Xia, "Clustering of Electricity Consumption Behavior Dynamics Toward Big Data Applications," IEEE Transactions on Smart Grid, vol. 7, no. 5, pp. 2437-2447, Sept. 2016.

[29] F. F. C. Veliz, C. L. T. Borges and A. M. Rei, "A Comparison of Load Models for Composite Reliability Evaluation by Nonsequential Monte Carlo Simulation," IEEE Transactions on Power Systems, vol. 25, no. 2, pp. 649-656, May 2010.

[30] K. R. Davis, C. M. Davis, S. A. Zonouz, et al., "A Cyber-Physical Modeling and Assessment Framework for Power Grid Infrastructures," IEEE Transactions on Smart Grid, vol. 6, no. 5, pp. 2464-2475, Sep. 2015.

[31] W. Kuo, M. Zuo. Optimal Reliability Modeling principles and applications, John Wiley \& Sons, 2003.

[32] R. Billinton, N. R. Allan, Reliability Evaluation of Engineering Systems, 
Concepts and Techniques, 2nd ed., Plenum Press, pp. 377-378, 1992.

[33] Y. Ding, P. Wang, "Reliability and price risk assessment of a restructured power system with hybrid market structure," IEEE Transactions on Power Systems, vol. 21, no. 1, pp. 108-116, Feb. 2006.

[34] A. Lisnianski, D. Elmakias, et al., "A multi-state Markov model for a short-term reliability analysis of a power generating unit," Reliability Engineering and System Safety, vol. 98, no. 1, pp. 1-6, Feb. 2012.

[35] A. I. Negash, T. W. Haring and D. S. Kirschen, "Allocating the Cost of Demand Response Compensation in Wholesale Energy Markets," IEEE Transactions on Power Systems, vol. 30, no. 3, pp. 1528-1535, May 2015.

[36] P. Wang, Y. Ding, and L. Goel. "Reliability assessment of restructured power systems using optimal load shedding technique." IET Generation Transmission \& Distribution, vol. 3, no.7, pp. 628-640, 2009.

[37] G. Tollefson, R. Billinton, G. Wacker, et al., "A Canadian customer survey to assess power system reliability worth," IEEE Transactions on Power Systems, vol. 9, no. 1, pp. 443-450, Feb. 1994

[38] M. J. Sullivan, M. G. Mercurio, and J. A. Schellenberg, "Estimated value of service reliability for electric utility customers in the United States," LBNL Research Project Final Report, Jun. 2009.

[39] R. Karki, Po Hu and R. Billinton, "A simplified wind power generation model for reliability evaluation," IEEE Transactions on Energy Conversion, vol. 21, no. 2, pp. 533-540, June 2006.

[40] R. Billinton, S. Kumar, N. Chowdhhury, K. Chu, K. Debnath, L. Goel, E. Khan, P. Kos, G. Nourbakhsh, and J. Oteng-Adjei, "A reliability test system for educational purposes- basic data," IEEE Transactions on Power Systems, vol. 4, no. 3, pp. 1238-1244, Aug. 1989.

[41] M. Panteli and D. S. Kirschen, "Assessing the effect of failures in the information and communication infrastructure on power system reliability," in 2011 IEEE/PES Power Systems Conference and Exposition, Phoenix, AZ, 2011, pp. 1-7. 